\title{
Security assessment of magnesium alloys used as biodegradable implant material
}

\author{
X Sun ${ }^{\mathrm{a}}$, Z.Y. Cao ${ }^{\mathrm{a},{ }^{*}}$, J.G. Liu ${ }^{\mathrm{b}}$ and C Feng ${ }^{\mathrm{c}}$ \\ ${ }^{a}$ Department of Materials Science and Engineering, Jilin University, Changchun 130025, China \\ ${ }^{b}$ Joint Surgery Department, Norman Bethune No.1 Hospital, Jilin University, Changchun 130000, \\ China \\ ${ }^{c}$ Changchun Limei Technology Development Company Limited, Changchun 130000, China
}

\begin{abstract}
The security risk of magnesium alloys used as biodegradable implant material was evaluated in this study. Doseresponse assessment was conducted by using toxicological data from authoritative public health agencies (World Health Organization) and assuming 1 3 years of uniform corrosion. Through modification calculation, the tolerable corrosion rate of biodegradable magnesium alloys in vivo was proposed, which theoretically ensured the bio-safety of the degradation products. The tolerable limits corresponding to various component elements in magnesium alloys were considered separately, although there are deficits in the toxicological data of some component elements. The influence of corrosion on the strength of magnesium alloys was evaluated, which would contribute to the rationally utilization of magnesium alloys as degradable implant materials. This study illustrates that not only toxicological calculations but also mechanical performance should be taken into consideration when developing novel degradable metallic implant.
\end{abstract}

Keywords: Risk assessment, biodegradation, magnesium alloys, biocompatibility

\section{Introduction}

In recent years, renewed interest in degradable/resorbable metallic implants emerged in the areas of bone fixation devices, cardiovascular stents and tissue engineering scaffolds [1,2]. Magnesium is itself considered relatively safe [3], and many series of magnesium alloys [4-6] had been developed for biodegradable materials application. However, the compositions of these alloys are very different and do not have a uniform alloying element selection criteria. Alloying elements such as aluminum (Al), zinc $(\mathrm{Zn})$, manganese $(\mathrm{Mn})$ and rare earth $(\mathrm{RE})$ are well known to carry substantial toxicological concerns [7-9]. Increasing evidence suggests that $\mathrm{Al}$ is a risk element for Alzheimer's disease [10] despite oppositions [11]. Even so, it is still unsure whether Al could be the unique factor. Therefore, it is crucial to implement toxicological risk assessment of magnesium alloys and set safety composition ranges for alloying elements, instead of just abandoning any possible toxic elements, as Al. Yuen and Ip [12] had conducted a theoretical risk assessment to compute the lowest mass of implant, which is suf-

\footnotetext{
* Address for correspondence: Z.Y. Cao, Department of Materials Science and Engineering, Jilin University, Changchun 130025, China. Tel./Fax: +86 431 85095852/+86 431 85095876; E-mail: caozy@jlu.edu.cn.
} 
ficient to avoid some adverse side effect in the view of professional medical science. However, the specific corrosion rate of alloys and the risk of gas released during degradation were not involved.

The biomechanical performance of magnesium alloys during corrosion is also noteworthy. Due to corrosion damage, the strength of alloys decreases with the extension of immersion time. Biodegradable implants need to perform the function of fixation and support during the corrosion process. The downward trend of strength during the corrosion process will affect the serving process of implants a lot and threaten the health of human body. Hence, the security assessment of magnesium alloys used as biodegradable implant materials was carried out in this paper. The research on the choice of alloying elements, the limited corrosion rate and the relation between strength and immersion time was implemented aiming to provide a reference for biological apply of magnesium alloys.

\section{Experimental procedure}

\subsection{Define the selection process of magnesium alloys used as biodegradable implant material}

The ideal biodegradable absorbent materials should be able to be completely degraded in vivo, and the degradation products are harmless to humans. Frank et al. presented a procedure about how to select appropriate magnesium alloys for intended implant [13]. According to this procedure and the standards issued by the World Health Organization (WHO) [14-17], the selection process of magnesium alloys used as biodegradable implants could be finally confirmed (see in Figure 1). In this selection process, both biocompatibility and biomechanical properties of magnesium alloys were taken into consideration.

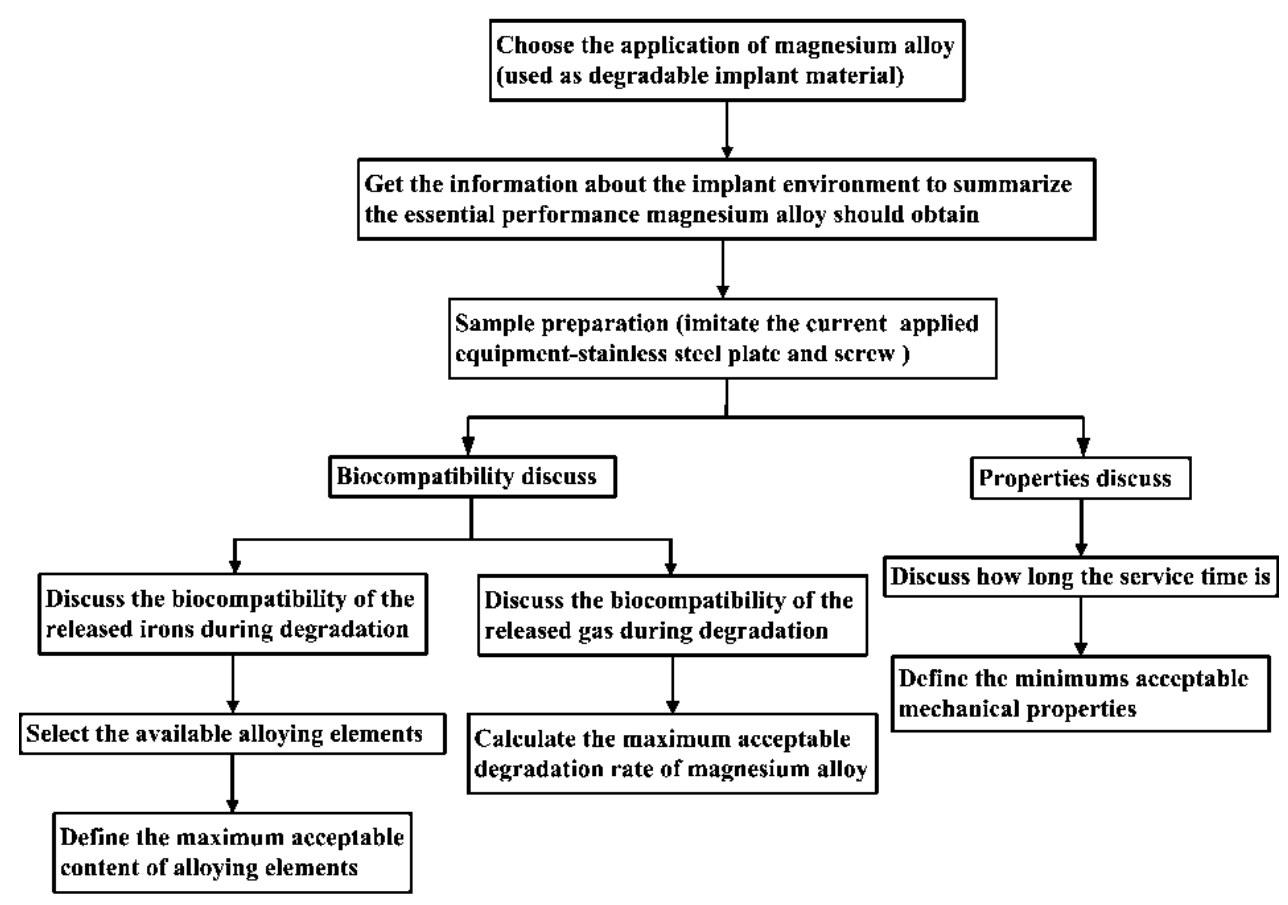

Fig. 1. The process to select appropriate magnesium alloys for degradable implant materials. 


\subsection{Model set}

Mg-2Mn-1Ca alloy was used to prepare implant plane and screw. The chemical composition (wt.\%) of Mg-2Mn-1Ca alloy is $1.908 \mathrm{Mn}, 0.944 \mathrm{Ca}, 0.005 \mathrm{Cu}, 0.005 \mathrm{Ni}, 0.005 \mathrm{Fe}$ and balance $\mathrm{Mg}$. The currently applied stainless steel plate $(178 \mathrm{~mm} \times 18 \mathrm{~mm} \times 5 \mathrm{~mm}, 88.16 \mathrm{~g})$ and screw $(\varnothing 5 \mathrm{~mm} \times 50 \mathrm{~mm}, 4.98 \mathrm{~g})$ were taken as a control group. Their surface areas were $83.68 \mathrm{~cm}^{2}$ and $3.925 \mathrm{~cm}^{2}$, respectively. Magnesium alloys plate $(24.45 \mathrm{~g})$ and screw $(1.16 \mathrm{~g})$ with the same dimensions of stainless steel ones were taken as experimental specimens.

F. Witte et al. [4] had implanted AZ91D intramedullary rods with a dimension of $\varnothing 1.5 \mathrm{~mm} \times 20 \mathrm{~mm}$ into both guinea pig femora. It was reported [4] that the subcutaneous bubbles in guinea pigs appeared within one week after surgery and disappeared after 2 to 3 weeks. The subcutaneous bubble is about $1 \mathrm{~cm}$ in diameter and $4 \mathrm{ml}$ in volume. No adverse effects generated on the guinea pigs, which indicated that a gas amount lower than $4 \mathrm{ml}$ is insignificant to the human body. McBride [14] reported in 1938 that the gas aspirated from a gas cavity 40 days after implanting a band of magnesium alloy showed a gas composition of $5.6 \% \mathrm{CO}_{2}, 6.5 \% \mathrm{O}_{2}, 7.3 \% \mathrm{H}_{2}$ and $80.6 \% \mathrm{~N}_{2}$. F. Witte [15] had also observed that the subcutaneous gas cavities contained only a low concentration of $\mathrm{H}_{2}$ even shortly after implantation. In this research, we will discuss the long-term gas diffusion process (more than 1 year) of the subcutaneous bubbles, so it may be more accurate to use the diffusion coefficient of $\mathrm{N}_{2}$ to calculate the diffusion process of the gas in the subcutaneous bubbles. With the above conclusions, a gas diffusion model was set to describe the diffusion flux $(J)$ of the subcutaneous bubble (mainly $\mathrm{N}_{2}$ ) produced by the degradation of biodegradable magnesium alloys. For a prior theoretical assessment, the degradation process of biodegradable magnesium alloys is assumed to be uniform.

\section{Results and discussion}

\subsection{Alloying elements selection}

In the metal smelting process, impurity elements like $\mathrm{Fe}, \mathrm{Cu}$ and $\mathrm{Ni}$ will be interfused. Some other elements like Al, $\mathrm{Zn}, \mathrm{Mn}$ and RE are added aiming to improve the performance of magnesium alloys. According to the publications issued by WHO [16, 17], Ca, Zn, Mn (essential trace elements for human body) and $\mathrm{Si}, \mathrm{Al}, \mathrm{RE}$ (probably essential elements for human body) were selected as potential safety alloying elements which can either improve the corrosion resistance or the mechanical properties of magnesium alloys.

\subsection{Define the degradation rate of biodegradable magnesium alloys}

For a pioneering theoretical assessment, it is assumed that the degradation process is uniform. The implanted stainless steel plate is usually removed about 1 year later when the patient's condition is recovered. Hence, when the degradation time is increased to the limit period (1 year) and does not exceed 3 years, the influence of the oral and potential inhalational intake of the elements from daily activities could be offset [18]. Therefore, the degradation time could be determined from 1 year to 3 years. Supposing a set of skeletal fixation needs one plate and six screws, the degradation rate $(D R)$ could be calculated as follows:

$$
D R=\frac{W}{A t}
$$


where $W$ is the weight loss of degradable magnesium alloys, $A$ is the exposure surface, which is about $107.23 \mathrm{~cm}^{2}$, and $t$ is the exposure time (1 3 years). When the implant Mg alloys was completely dissolved, $W$ is the whole weight of the skeletal fixation set, which is about $31.41 \mathrm{~g}$. By substituting the actual values into Eq. (1), it is indicated that the tolerant limit degradation rate of different degradation time is from 0.0111 to $0.0334 \mathrm{mg} / \mathrm{cm}^{2} \cdot \mathrm{h}$. Compared with the corrosion rate of pure magnesium (3.0 $\mathrm{mm} /$ year $\approx 0.059 \mathrm{mg} / \mathrm{cm}^{2} \cdot \mathrm{h}$ ) in simulated body fluid (SBF) [19], the degradation rate of biodegradable magnesium alloys in vivo is about a fifth lower. It had been demonstrated by experiment that the degradation rate of magnesium alloys in vivo was about four orders of magnitude lower than that in vitro [20]. Y. Xin et al. also concluded that although the SBF consists of inorganic ions with concentration similar to those in body plasma, the lower concentration of buffering agents and much lower concentration of $\mathrm{HCO}_{3}^{-}(\sim 4.0 \mathrm{~mol} / \mathrm{L})$ impede the acquisition of more accurate measurement in vitro degradation like that in the human body [21]. Therefore, when considering the degradation rate in vitro, the results still need to be adapted by a correction factor in various physiological conditions. To have a high safety coefficient, the calculated degradation rate in vivo will be regard as the one in vitro in the following research.

\subsection{Define the mixture ratio of alloy elements}

Because of the limits of maximum daily allowable dosage from Table 1, 400 milligram (mg) $\mathrm{Mg}$ was taken as matrix. Hence, the maximum acceptable content $(M A C)$ of other elements in biodegradable magnesium alloys could be calculated as follows:

$$
M A C=\frac{m}{400+m}
$$

where $m$ is the maximum acceptable daily intake of each element. By using the existing data, the modified maximum acceptable content $\left(M A C_{C}\right)$ of each element can be calculated as follows:

$$
\begin{aligned}
& m_{n}=A \times D R_{n} \\
& M A C_{c}=\frac{D R_{n} \times M A C}{D R}
\end{aligned}
$$

where $D R_{n}$ is the actual corrosion rate of different magnesium alloys reported in previous studies [20, 24-26], $m_{n}$ is the actual daily corrosion dosage calculated from $D R_{n} . M A C_{C}$ gives us a wider scope to choose the suitable content of alloying elements in biodegradable magnesium alloys. The details are listed in Table 2.

Table 1

Summary of toxicity quoted in the open literature for elements relevant to magnesium alloys implant materials [14, 22, 23]

\begin{tabular}{lllllllllll}
\hline Element & $\mathrm{Mg}$ & $\mathrm{Al}$ & $\mathrm{Zn}$ & $\mathrm{Mn}$ & $\mathrm{Li}$ & $\mathrm{Si}$ & $\mathrm{Y}$ & $\mathrm{RE}$ & $\mathrm{Nd}$ & $\mathrm{Ca}$ \\
\hline $\begin{array}{l}\text { Maximum Daily Allowable } \\
\text { Dosage(mg) }\end{array}$ & 400 & 14 & 15 & 3.5 & 0.1 & 120 & $0.016^{*}$ & $4.2^{*}$ & $4.2^{*}$ & 1400
\end{tabular}

Note: *denotes that the total amount of rare earth elements (Ce La Nd Pr and Y) combined should not exceed a value of 4.2 $\mathrm{mg} / \mathrm{d}$ 
Table 2

A brief summary of experimentally determined corrosion rates of different magnesium alloys and the results of modified maximum allowable content of different alloying elements [20, 24-26]

\begin{tabular}{|c|c|c|c|c|c|c|c|c|}
\hline Element & $\mathrm{Al}$ & $\mathrm{Zn}$ & $\mathrm{Mn}$ & $\mathrm{Li}$ & $\mathrm{Si}$ & $\mathrm{Y}$ & $\mathrm{RE}$ & $\mathrm{Ca}$ \\
\hline $\begin{array}{l}\text { MAC/The Maximum } \\
\text { Allowable content (wt.\%) }\end{array}$ & 3.38 & 3.6 & 0.86 & 0.025 & 23 & limited & 1.04 & unlimited \\
\hline Alloy Designation & AZ31 & AZ31 & $\mathrm{Mg}-0.5 \mathrm{Mn}$ & LA92 & - & - & JDM & $\mathrm{Mg}-1 \mathrm{Ca}$ \\
\hline $\begin{array}{l}\text { Electrolyte } \\
\text { Composition }\end{array}$ & In vivo & In vivo & Hanks sol & Hanks sol & - & - & SBF & In vivo \\
\hline Alloy State & cast & cast & cast & cast & - & - & extruded & cast \\
\hline Actual Content (wt.\%) & 3 & 0.99 & 0.5 & 8.6 & - & - & 3.09 & 1.34 \\
\hline $\begin{array}{l}D R_{n} / \text { Actual Corrosion } \\
\text { Rate }\left(\mathrm{mg} / \mathrm{cm}^{2} / \mathrm{h}\right)\end{array}$ & 0.013 & 0.013 & 0.02 & 0.001 & - & - & 0.0168 & 0.026 \\
\hline $\begin{array}{l}m_{n} / \text { Actual Daily Corrosion } \\
\text { Dosage of Alloy }(\mathrm{mg} / \mathrm{d})\end{array}$ & 33.456 & 33.456 & 51.470 & 2.573 & - & - & 43.235 & 66.912 \\
\hline \multirow{3}{*}{$\begin{array}{l}M A C_{C} / \text { The Modified Maximum } \\
\text { Allowable Content (wt.\%) }\end{array}$} & $1 y 1.316$ & 1.401 & 0.515 & 0 & - & - & 0.523 & unlimited \\
\hline & $2 y \quad 2.631$ & 2.802 & 1.03 & 0 & - & - & 1.034 & unlimited \\
\hline & $3 y \quad 3.959$ & 4.212 & 1.55 & 0.002 & - & - & 1.574 & unlimited \\
\hline
\end{tabular}

Note: 1y means the degradation time of biodegradable magnesium alloy is one year, the same meaning for $2 \mathrm{y}, 3 \mathrm{y}$.
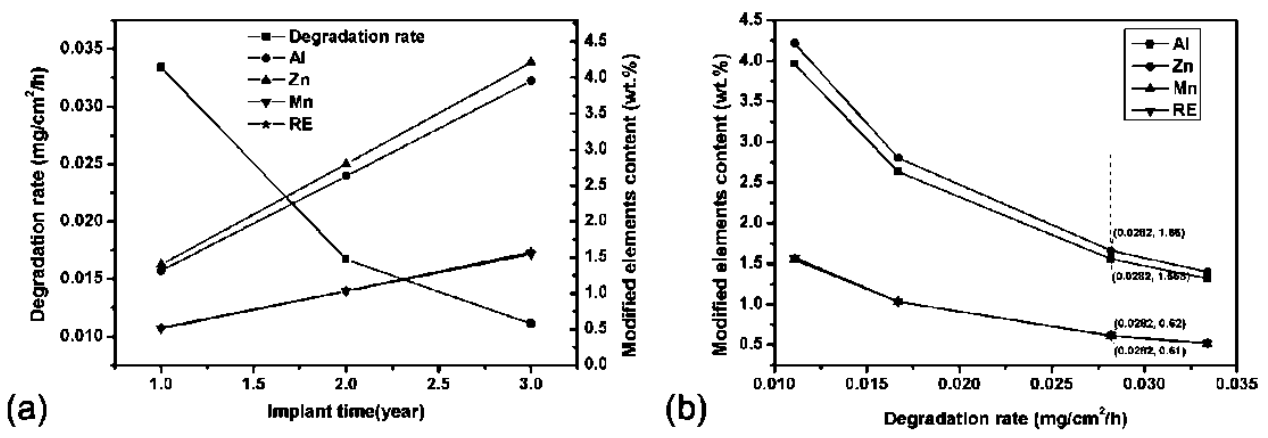

Fig. 2. (a) The influence of implant time on the tolerable degradation rate and alloying element content. (b) The relation between degradation rate and modified alloying element content.

From the above research, it could be concluded that the acceptable degradation rate of biodegradable magnesium alloys must be less than $0.0334 \mathrm{mg} / \mathrm{cm}^{2} \cdot \mathrm{h}$. As potential safety elements, proper amount of $\mathrm{Al}, \mathrm{Ca}, \mathrm{Zn}, \mathrm{Mn}$ and $\mathrm{RE}$ could be used to improve the comprehensive performance of magnesium. The limiting factor for the tolerable implant mass of common magnesium alloys was usually aluminum. Yuen and Ip suggested that the tolerable mass of aluminum below or around $1 \mathrm{~g} / \mathrm{year}$ might be inadequate for applications such as larger internal fixing devices for bone fractures [17]. However, in this research, it is indicated that if the content aluminum could be limited within a safe range (less than 
1.3 wt. \%) in Mg alloys, it could be both harmless to human bodies and enhance the mechanical properties and corrosion resistance of $\mathrm{Mg}$ alloys. For the other component elements such as zirconium and rare earth metals, although reliable theoretical assessment could not yet be performed owing to a deficiency of toxicological data, the results from Yuen and Ip are similar to ours. Certainly, more toxicological studies of such elements should be proceeded to ensure the bio-safety of their usage in degradable biomedical implants in the future. Base on the modification calculation, the influence of degradation time on $D R$ and $M A C_{C}$ was summarized in Figure 2.

\subsection{Security discussion of gas release}

Besides ions, the degradation products of magnesium alloys also contain hydrogen. The released hydrogen will converge into gas pockets under the subcutaneous tissues. The gas pockets next to implant will cause separation between the tissues and the tissue layers, which will lead to necrosis in the surgery regions. Therefore, the hydrogen evolution rate must be controlled within the safe range to ensure the clinical progress is satisfactory.

The environment, where biodegradable magnesium alloy plate is implanted, keeps continuously updating because of the flowing of tissue fluid. This situation belongs to the steady state diffusion, and the Fick's first law is applicable. The diffusion rate of subcutaneous bubble in muscle tissue could be calculated by the following formula:

$$
\begin{aligned}
J & =-D \frac{d C}{d X}=-D \frac{\Delta C}{\Delta X} \\
K & =S \cdot J
\end{aligned}
$$

where $J$ is the diffusion flux, $D$ is the diffusion coefficient, $C$ is the concentration of dissolved gas, $X$ is the distance, $S$ is the surface area of subcutaneous bubbles and $K$ is the rate of nitrogen diffusion into tissue fluid. The value of $D$ in the medium of skeletal muscle is $\sim 1.3 \times 10^{-5} \mathrm{~cm}^{2} / \mathrm{s}$ [27].

According to Eqs. (5) and (6), the diffusion rate of nitrogen in muscle tissue could be calculated, which is $\sim 0.00033 \mathrm{ml} / \mathrm{s}$. According to the chemical reaction $\mathrm{Mg}+\mathrm{H}_{2} \mathrm{O} \rightarrow \mathrm{Mg}(\mathrm{OH})_{2}+\mathrm{H}_{2} \uparrow, 1 \mathrm{ml}$ of $\mathrm{H}_{2}$ evolved corresponds to $1 \mathrm{mg}$ of magnesium dissolved [28]. Therefore, the gas diffusion rate limits the gas generation rate (equal to the degradation rate of magnesium alloys) to $0.0282 \mathrm{mg} / \mathrm{cm}^{2} \cdot \mathrm{h}$, which will assure the subcutaneous bubbles to keep in a steady size. The endurance of human body to the diffusion gas also needs to be taken into consideration. The blood flow rate in human muscle is $38 \mathrm{ml} / \mathrm{min} / 100 \mathrm{~g}$ and the Ostwald solubility coefficient $L$ ( $\mathrm{ml}$ gas per $\mathrm{ml}$ medium) for nitrogen in marrow of ox is $\sim 0.065$ at $37^{\circ} \mathrm{C}$ [13]. Hence, the ability of tissue fluid to transport nitrogen is $0.004 \mathrm{ml} / \mathrm{s} / 100 \mathrm{~g}$, which is higher than the gas diffusion rate. In conclusion, a corrosion rate of $0.0282 \mathrm{mg} / \mathrm{cm}^{2} \cdot \mathrm{h}$ or below is safe for the human body both in consideration of the toxic of ions and the body tolerance to hydrogen.

\subsection{Security discussion of biomechanical property}

As a load-carrying structure, biodegradable magnesium alloys implants need to perform the function of fixation and supporting roles during the degradation process. Bones in different sites of body have different tensile strength between $30 \sim 280 \mathrm{MPa}$ [29]. In this research, the magnesium alloy plate is aimed to be applied on tibia whose tensile strength is about $150 \mathrm{MPa}$. The formation of new bones usually begins in one month after surgery. Before the new bone formed, magnesium alloy needs to compensate the strength of broken bones. Therefore, it is significant to investigate the mechanical per- 
formance of biodegradable magnesium alloys in the process of degradation to demonstrate the reliability of implants. By experimental method and FE simulation predictions, Grogan et al. determined the relation of immersion time, mass loss and specimen strength [30]. In Grogan's research, the thickness of the specimen is $0.21 \mathrm{~mm}$ and the morphology of specimens after immersion test was shown. The corrosion process could be divided into two periods, the rapid decrease period and the relative stable period. In the first period, the pitting holes have serious negative impacts on the strength, which could be explained by fracture mechanics by using the stress intensity factor $K_{I}$ :

$$
K_{I}=2 \sigma \sqrt{\frac{r}{\pi}}
$$

where $\sigma$ is the axial tensile stress (MPa), $r$ is the depth of the deepest pitting hole (mm). When $K_{I} \geq$ $K_{I C}\left(\sim 55 \mathrm{MPa} \cdot \mathrm{mm}^{-1 / 2}\right)$ and the pitting holes had extended through the sample ( $r$ is $\left.0.21 \mathrm{~mm}\right), \sigma$ will decreases to $106.3 \mathrm{Mpa}$ according to Eq. (7). In this case, the pitting hole formed by corrosion could be regarded as a crack and suffered stress concentration near the tips. Then, the strength of magnesium alloys was controlled by the deepest depth of the pitting holes, and strength decreases dramatically with little mass loss. After the strength decreased to $106.3 \mathrm{MPa}$, the corrosion process comes to the slow decline period, that is, the second corrosion period. In this period, pitting holes had extended through the specimen and formed cylindrical holes drilled through the cross-section. The main influence factor of the decrement of strength changed from the depth of pitting holes to the area fraction of defects in the cross-section, and the decrement rate of strength is relatively slow. Hence, it could be concluded that it is the localized corrosion that seriously affects the strength of specimen. To improve localized corrosion resistance of magnesium alloys can efficiently avoid the failure of magnesium alloys during the serving process. Surface treatment is a good way to improve the localized corrosion resistance of materials. Additionally, when using magnesium alloys as biodegradable implant material, the dimension and the serving time of the implants also need to be rationally designed.

\section{Conclusion}

In this paper, the tolerable degradation rate and alloy composition of biodegradable magnesium alloys were investigated based on current standards. In this contribution, it could be summarized that $0.0282 \mathrm{mg} / \mathrm{cm}^{2} \cdot \mathrm{h}$ is an acceptable degradation rate of magnesium alloys in vitro. The suggested contents (wt. \%) of $\mathrm{Al}, \mathrm{Zn}, \mathrm{Ca}, \mathrm{Mn}$ and $\mathrm{RE}$ acted as potential safety alloying elements are 1, 1, 1, 1.5 and 1.5 , respectively. The influence of corrosion on the material strength could be divided into two periods. In the first period, it is the depth of pitting holes that affected the material strength most. In the second stage, the decrease of material strength is slow, which is mainly affected by the fraction of defects introduced into the cross-sectional area. Knowing the relationship between localized corrosion and material strength will help people a lot to proper design and utilize biodegradable magnesium alloy implants. 


\section{Acknowledgments}

This work is supported by the "985 Project" of Jilin University, the Science and Technology Program of Jilin Province (201105007) and the Open Subject of State Key Laboratory of Rare Earth Resource Utilization (RERU2011001).

\section{References}

[1] C.E. Wen, M. Mabuchi, Y. Yamada, K. Shimojima, Y. Chino and T. Asahina, Processing of biocompatible porous Ti and Mg, Scripta Materialia 45 (2001), 1147-1153.

[2] C.E. Wen, Y. Yamada, K. Shimojima, Y. Chino, H. Hosokawa and M. Mabuchi, Porous bioresorbable magnesium as bone substitute, Materials Science Forum 419 (2003), 1001-1006.

[3] M.P. Staiger, A.M. Pietak, J. Huadmai and G. Dias, Magnesium and its alloys as orthopedic biomaterials: A review, Biomaterials 27 (2006), 1728-1734.

[4] F. Witte, V. Kaese, H. Haferkamp, E. Switzer, A. Meyer-Lindenberg, C.J. Wirth and H. Windhagen, In vivo corrosion of four magnesium alloys and the associated bone response, Biomaterials 26 (2005), 3557-3563.

[5] L Yang and E Zhang, Biocorrosion behavior of magnesium alloy in different simulated fluids for biomedical application, Materials Science and Engineering C 29 (2009), 1691-1696.

[6] W. Zhang, M. Li, Q. Chen, W. Hua, W. Zhang and W. Xin, Effects of Sr and Sn on microstructure and corrosion resistance of Mg-Zr-Ca magnesium alloy for biomedical applications, Materials Design 39 (2012), 379-383.

[7] N. Roney, C.V. Smith, M. Williams, M. Osier and S.J. Paikoff, Toxicological profile for zinc, Available at http://www.atsdr.cdc.gov/toxprofiles/tp60. pdf: 2005.

[8] S. Keith, D. Jones, Z. Rosemond, L. Ingerman and L. Chappell, Toxicological profile for aluminum, Available at http://www.atsdr.cdc.gov/toxprofiles/tp22. pdf: 2008.

[9] M. Williams-Johnson, K.B. Altshuler, S.W. Rhodes and L. Kolb, Toxicological profile for manganese, Available at http://www.atsdr.cdc.gov/toxprofiles/tp151. pdf: 2000.

[10] P.C. Ferreira, A. Piai Kde, A.M. Takayanagui and S.I. Segura-Munoz, Aluminum as a risk factor for Alzheimer's disease, Revista Latino-America De Enfermagem 16 (2008), 151-157.

[11] T. Mizoroki, S. Meshitsuka, S. Maeda, M. Murayama, N. Sahara and A. Takashima, Aluminum induces tau aggregation in vitro but not in vivo, Journal of Alzheimer's Disease 11 (2007), 419-427.

[12] C.K. Yuen and W.Y. Ip, Theoretical risk assessment of magnesium alloys as degradable biomedical implants, Acta Biomaterialia 6 (2010), 1808-1812.

[13] F. Wittea, N. Hort, C. Vogtd, S. Cohen, K.U. Kainer, R. Willumeit and F. Feyerabend, Degradable biomaterials based on magnesium corrosion, Current Opinion in Solid State and Materials Science 12 (2008), 63-72.

[14] D. Earl and E.D. McBride, Absorbable metal in bone surgery: A further report on the use of magnesium alloys, Jama-Journal of the American Medical Association 111 (1938), 2464-2467.

[15] J. Kuhlmann, I. Bartsch, E. Willbold, S. Schuchardt, O. Holz, N. Hort, D.Höche, W.R. Heineman and F. Witte, Fast escape of hydrogen from gas cavities around corroding magnesium implants, Acta biomaterialia 9 (2013), 8714-8721.

[16] Trace Elements in Human Nutrition and Health, World Health Organization, Geneva, 1996.

[17] Assessing human health risks of chemicals: derivation of guidance values for health-based exposure limits, World Health Organization, Geneva, 1994.

[18] ASTM, F1983-99 (Reapproved 2003) standard practice for assessment of compatibility of absorbable/resorbable biomaterials for implant applications, West Conshohocken, PA: ASTM International, 2003.

[19] Y. Wang, M. Wei, J. Gao, J. Hu and Y. Zhang, Corrosion process of pure magnesium in simulated body fluid, Materials letters 62 (2008), 2181-2184.

[20] F. Witte, J. Fischer, J. Nellesen, H.A. Crostack, V. Kaese, A. Pisch, F. Beckmann and H. Windhagen, In vitro and in vivo corrosion measurements of magnesium alloys, Biomaterials 27 (2006), 1013-1018.

[21] Y. Xin, T. Hu and P.K. Chu, In vitro studies of biomedical magnesium alloys in a simulated physiological environment: A review, Acta Biomater 7 (2011), 1452-1459.

[22] F. Witte, I. Abeln, E. Switzer, V. Kaese, A. Meyer-Lindenberg and H. Windhagen, Evaluation of the skin sensitizing potential of biodegradable magnesium alloys, Journal of Biomedical Materials Research Part A 86 (2008) 1041-1047. 
[23] N. Roney, C.V. Smith, M. Williams, M. Osier and S.J. Paikoff, Toxicological profile for zinc, Available at http://www.atsdr.cdc.gov/toxprofiles/tp60. pdf: 2005.

[24] X. Gu, Y. Zheng, Y. Cheng, S. Zhong and T. Xi, In vitro corrosion and biocompatibility of binary magnesium alloys, Biomaterials 30 (2009), 484-498.

[25] D. Yin, E. Zhang and S. Zeng, Effect of Zn on mechanical property andcorrosion property of extruded Mg-Zn-Mn alloy, Transactions of Nonferrous Metals Society of China 18 (2008), 763-768.

[26] Z. Li, X. Gu, S. Lou and Y. Zheng, The development of binary Mg-Ca alloys for use as biodegradable materials within bone, Biomaterials 29 (2008), 1329-1344.

[27] T. Lango, T. Morland and A.O. Brubakk, Diffusion coefficients and solubility coefficients for gases in biological fluids and tissues: A review, Undersea and Hyperbaric Medicine 23 (1996), 247-272.

[28] G. Song, Control of biodegradation of biocompatable magnesium alloys, Corrosion Science 49 (2007), 1696-1701.

[29] F. Witte, N. Hort, C. Vogt, S. Cohen, K.U. Kainer and R. Willumeit, Degradable biomaterials based on magnesium corrosion, Current Opinion Solid State and Materials Science 12 (2008), 63-72.

[30] J.A. Grogan, B.J. O'Brien, S.B. Leen and P.E. McHugh, A corrosion model for bioabsorbable metallic stents, Acta Biomaterialia 7 (2011), 3523-3533. 